\title{
Paclitaxel combined with harmine inhibits the migration and invasion of gastric cancer cells through downregulation of cyclooxygenase- 2 expression
}

\author{
KUN SUN, XIAO-HE TANG and YI-KUI XIE \\ Department of Gastroenterology, The First Hospital of Zibo, Zibo, Shandong 255200, P.R. China
}

Received September 12, 2014; Accepted May 20, 2015

DOI: $10.3892 / \mathrm{ol} .2015 .3425$

\begin{abstract}
Cyclooxygenase-2 (COX-2) has a critical role in the invasiveness and metastasis of gastric cancer. In addition, paclitaxel (PTX) and harmine (HM) were reported to be potential therapeutic drug candidates for cancer therapy; however, the synergistic antitumor effect of PTX and HM combined treatment on the human gastric cancer cells remains to be elucidated. The aim of the present study was to evaluate the effects of PTX and/or HM on the cell migration and invasion in two human gastric cancer cell lines, SGC-7901 and MKN-45. MTT assay was used to detect the growth inhibition induced by PTX and HM . The Transwell assay was employed to assess the effects of PTX and HM on the cell migration and invasion. The expression levels of COX-2 and matrix metalloproteinase-9 (MMP-9) were analyzed by western blot analysis. The results demonstrated that PTX and HM inhibited cell proliferation in a dose-dependent manner. Individually PTX and HM were able to inhibit the migration and invasion of two human gastric cancer cells; however, the combination of PTX and HM exerted synergistic effects on migration and invasion inhibition, with downregulation of COX-2 and matrix metalloproteinase (MMP)-9. In conclusion, the results of the present study indicated that combination chemotherapy using PTX with HM exerted an antitumor effect, which may be implicated for the treatment of gastric cancer. Of note, the combination of the two drugs inhibited migration and invasion more effectively compared with each drug alone, the mechanism of which proceeded via the downregulation of COX-2 expression.
\end{abstract}

Correspondence to: Dr Kun Sun or Dr Yi-Kui Xie, Department of Gastroenterology, The First Hospital of Zibo, 4 Emeishan East Road, Boshan District, Zibo, Shandong, 255200, P.R. China

E-mail: petersun1987@163.com

Email: xyk6351@163.com

Key words: paclitaxel, harmine, cyclooxygenase-2, gastric cancer, metastasis

\section{Introduction}

Gastric cancer is one of the most prominent causes of cancer-associated mortalities worldwide (1). At present, surgical resection and chemotherapy are the two major means of treating gastric cancer. Despite improvements in treatment, the prognosis of patients with advanced gastric cancer following curative resection remains poor, mainly as a result of local or distant metastasis (2). Therefore, the elucidation of novel drugs or combination chemotherapies for gastric cancer treatment are urgently required $(1,2)$. As a standard anticancer drug, paclitaxel (PTX) has an important role in the treatment of a variety of tumors, including gastric cancer. As previously reported, the efficiency of the single anticancer drug paclitaxel was $11-23 \%$ for treating advanced-stage gastric cancer, while that of drug combination therapy reached 50-60\% (3). Peganum harmala had been used for numerous years in traditional medicine in China and other parts of the world. Harmine (HM), a tricyclic compound found in Peganum harmala and belonging to the $\beta$-carboline alkaloids, has been proven to possess antitumor properties and was previously examined for its potential use for cancer therapy $(4,5)$. It was reported that HM effectively inhibited tumor migration and invasion in vitro (6). However, the synergistic antitumor effect of a combination of PTX and $\mathrm{HM}$ on migration and invasion of human gastric cancer cells remains to be elucidated.

Cyclooxygenase (COX), also termed prostaglandin synthase, is the rate-limiting enzyme which enables the conversion of arachidonic acid to prostaglandins. COX exists as two isoforms, including the constitutive COX-1 and the mitogen-inducible $\mathrm{COX}-2$. In gastric cancer, $\mathrm{COX}-2$ is continuously expressed and was reported to be closely associated with tumor invasiveness and metastasis $(7,8)$. Previous studies have demonstrated that the inhibition of COX-2 by selective COX-2 inhibitors or small interfering RNA (siRNA) may attenuate proliferation and induce apoptosis in human gastric cancer cells $(9,10)$. It has been reported that HM inhibited gastric cancer cell migration and invasion through the downregulation of COX-2 expression.

The matrix metalloproteinase (MMP) family consists of a group of closely associated enzymes involved in the cleavage of structural components of the extracellular matrix (ECM); these enzymes are considered to be essential factors involved in 
tumor invasion and metastasis (11,12). In gastric cancer, MMP-9 and MMP-2 were reported to be overexpressed and associated with tumor aggressiveness $(11,12)$. In addition, a previous study demonstrated that MMP-9 expression was significantly correlated with COX-2 expression in human gastric cancer.

The aim of the present study was to evaluate whether the combination of PTX and HM exerted synergistic antitumor effects on the migration and invasion of two human gastric cancer cell lines, SGC-7901 and MKN-45, in which COX-2 is known to be expressed (13). In addition, the present study aimed to explore the possible mechanism by which this effect may proceed.

\section{Materials and methods}

Reagents. PTX, HM (purity, >98\%), dimethyl sulfoxide (DMSO) and 3-(4,5-dimethylthiazol-2-yl)-2,5-diphenyl tetrazolium bromide (MTT) were obtained from Sigma-Aldrich (St. Louis, MO, USA). The chemical structures of PTX and HM are shown in Fig. 1. Stock solutions of PTX and HM were diluted in DMSO $(\leq 0.1 \%)$ and sterilized by passage through a $0.22-\mu \mathrm{m}$ pore size filter (Immobilon ${ }^{\circledR}$; EMD Millipore Corp., Bedford, MA, USA), then diluted with culture media prior to use. RPMI-1640 medium, fetal bovine serum (FBS) and penicillin/streptomycin were obtained from Gibco BRL (Grand Island, NY, USA). All other chemicals were of analytical grade and used without further purification.

Cell lines and culture. Human poorly-differentiated MKN-45 and moderately-differentiated SGC-7901 gastric cancer cell line were purchased from the Shanghai Institute of Cell Biology (Shanghai, China). Cells were cultured in RPMI-1640 medium supplemented with 10\% FBS, $100 \mathrm{U} / \mathrm{ml}$ penicillin $\mathrm{G}$ and $100 \mu \mathrm{g} / \mathrm{ml}$ streptomycin at $37^{\circ} \mathrm{C}$ in a humidified incubator with $5 \% \mathrm{CO}_{2}$.

MTT cell proliferation assay. SGC-7901 and MKN-45 cells $\left(200 \mu \mathrm{l} /\right.$ well) were seeded at a density of $1 \times 10^{4}$ cells in 96-well plates and incubated overnight in 10\% FBS medium. Cells were then administered various concentrations of PTX or HM, alone or in combination, in serum-free conditions. The control group consisted of cells incubated in serum-free medium. Following $48 \mathrm{~h}$ of incubation at $37^{\circ} \mathrm{C}$, $20 \mu 1$ MTT solution $[5 \mathrm{mg} / \mathrm{ml}$ in phosphate buffered saline (PBS)] was added to each well and incubated for a further $4 \mathrm{~h}$ at $37^{\circ} \mathrm{C}$. Subsequently, $100 \mu 1 \mathrm{DMSO}$ was added into each well and incubated at $37^{\circ} \mathrm{C}$ for $2 \mathrm{~h}$. Optical density (OD) values were measured using a spectrophotometer (FLx800; Bio-Rad Laboratories, Inc., Hercules, CA, USA) at $570 \mathrm{~nm}$. All experiments were performed in triplicate and the results are presented as the percentages relative to the controls.

In vitro Transwell ${ }^{\circledR}$ migration assays. Migration assays were performed in 24-well Transwell ${ }^{\oplus}$ chambers (Corning Life Sciences, Inc., Tewksbury, MA, USA) without Matrigel ${ }^{\circledR}$ In brief, SGC-7901 and MKN-45 cells were allowed to grow to $80 \%$ confluence and were serum-starved for $48 \mathrm{~h}$ at $37^{\circ} \mathrm{C}$ in a humidified incubator with an atmosphere of $5 \%$ $\mathrm{CO}_{2}$. Following detachment using trypsin (Sigma-Aldrich), the cells in different groups were washed with PBS, resuspended
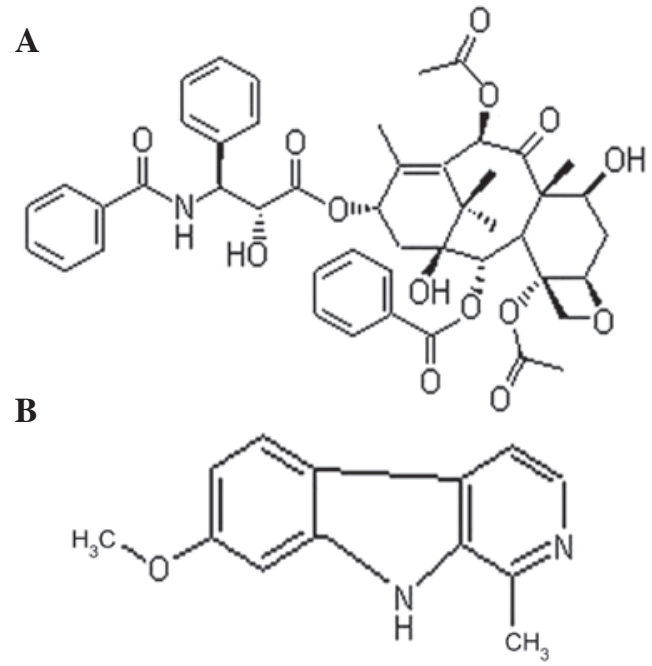

Figure 1. Chemical structures of (A) paclitaxel and (B) harmine.

in serum-free medium and $1 \times 10^{5}$ cells/group were added to the upper chamber. Complete medium was added to the bottom chamber as a chemoattractant. Unmigrated cells on the upper surface of the filter were mechanically removed using a cotton swab and the invasive cells on the bottom membrane surface were then fixed with methanol (Grand Island, NY, USA) and stained with $0.1 \%$ crystal violet (Immobilon, Millipore Corp., Bedford, MA, USA). The migrating cells were counted and images were captured using a microscope (magnification, x100; Eclipse E800; Nikon Corporation, Tokyo, Japan). All experiments were performed in triplicate and nine fields of vision were counted per filter in each group.

In vitro Transwell ${ }^{\circledast}$ invasion assays. Invasion assays were performed in 24-well Transwell ${ }^{\circledR}$ chambers containing polycarbonate filters with $8-\mu \mathrm{m}$ pores coated with Matrigel ${ }^{\mathbb{B}}$ (BD Biosciences, Bedford, MA, USA). The remaining steps were identical to those described for the Transwell ${ }^{\circledR}$ migration assays.

Western blot analysis. Cells were treated with $2 \mathrm{ng} / \mathrm{ml}$ PTX, $4 \mu \mathrm{g} / \mathrm{ml} \mathrm{HM}$ or a combination of these two drugs for $48 \mathrm{~h}$ at $37^{\circ} \mathrm{C}$ in a humidified incubator with an atmosphere of $5 \% \mathrm{CO}_{2}$. Cells were then washed twice with ice-cold PBS and protein extraction was performed by lysis in RIPA buffer $[150 \mathrm{mM} \mathrm{NaCl}, 1 \%$ (v/v) NP-40, 0.5\% (w/v) sodium deoxycholate, $0.1 \%(\mathrm{w} / \mathrm{v})$ sodium dodecyl sulfate (SDS), $50 \mathrm{mM}$ Tris $\mathrm{HCl}$ (pH 8), $10 \mathrm{mM}$ EDTA and $1 \mathrm{mM}$ phenylmethylsulfonyl fluoride; Sigma-Aldrich] for $30 \mathrm{~min}$ at $4^{\circ} \mathrm{C}$, followed by centrifugation for $15 \mathrm{~min}$ at $12,000 \mathrm{x}$ g. Protein concentrations were determined using a bicinchoninic acid assay (Pierce Biotechnology, Inc., Rockford, IL, USA) according to the manufacturer's instructions. Subsequently, proteins $(60 \mu \mathrm{g})$ were loaded onto a $10 \%(\mathrm{w} / \mathrm{v})$ SDS-polyacrylamide gel, electrophoresed and transferred onto a polyvinylidene fluoride membranes (EMD Millipore Corp., Billerica, MA, USA) which was then blocked for $2 \mathrm{~h}$ at room temperature with blocking buffer [Tris-buffered saline containing $0.1 \%(\mathrm{v} / \mathrm{v})$ Tween 20 (Sigma-Aldrich) and 5\% (w/v) milk powder]. The following primary antibodies $(1: 1,000)$ 
A

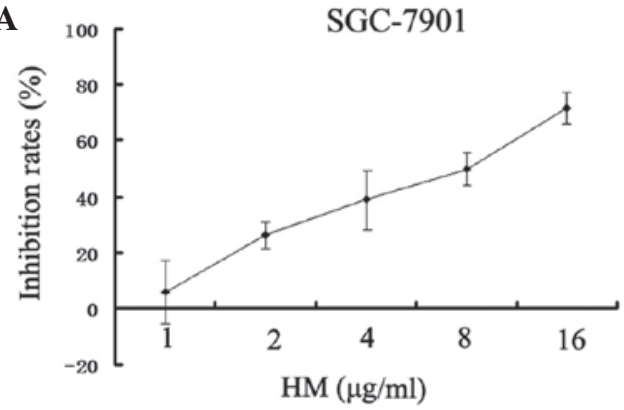

\section{B}
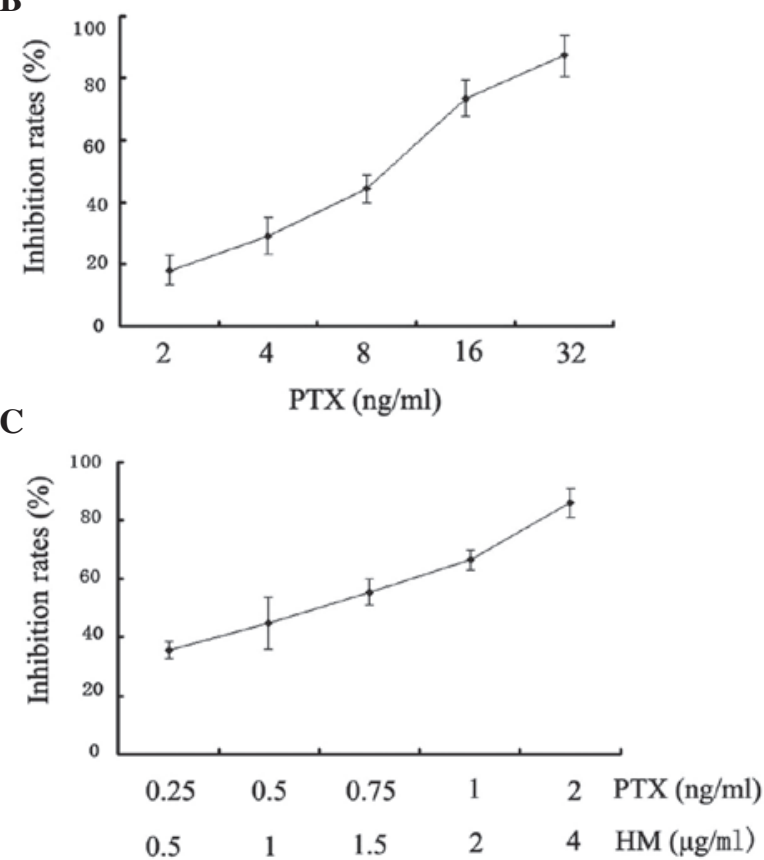
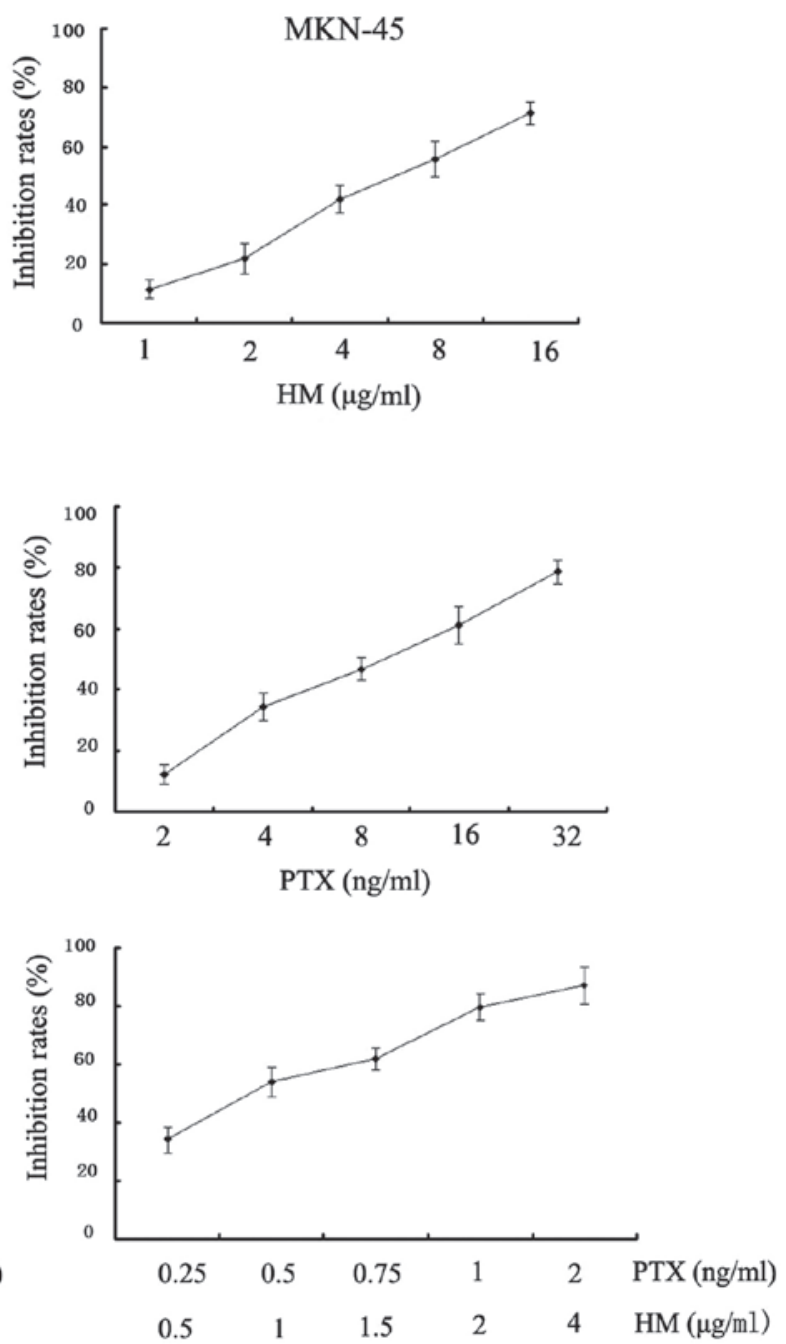

Figure 2. Effects of PTX and/or HM on cell proliferation in SGC-7901 and MKN-45 gastric cancer cells, as determined using an MTT assay. Dose-dependent effects of the indicated concentrations of (A) PTX and (B) HM on gastric cancer cell proliferation. (C) Combined effects of PTX and HM at the indicated concentrations on cell proliferation in SGC-7901 and MKN-45 cells. Values are presented as the percentage inhibition rate relative to the control group (0\%). PTX, paclitaxel; HM harmine.

were applied for $1 \mathrm{~h}$ at room temperature or overnight at $4^{\circ} \mathrm{C}$ : Polyoclonal rabbit anti-mouse COX-2 (cat. no. 13314; Cell Signaling Technology, Inc., Beverly, MA, USA), polyclonal rabbit anti-mouse MMP-9 (cat. no. sc-21733; Santa Cruz Biotechnology, Inc., Dallas, TX, USA) and polyclonal rabbit anti-mouse GAPDH (cat. no. G5262; Sigma-Aldrich). Membranes were then incubated for $2 \mathrm{~h}$ with polyclonal goat anti-rabbit horseradish peroxidase-conjugated secondary antibodies (1:20,000; cat. no. BA-1000; Vector Laboratories, Inc., Burlingame, CA, USA) at $37^{\circ} \mathrm{C}$ in a humidified incubator with an atmosphere of $5 \% \mathrm{CO}_{2}$. Membranes were then visualized using an enhanced chemiluminescence kit and signals were quantified by scanning densitometry (Quantity One software; Bio-Rad Laboratories, Inc.). The relative expression levels of COX-2 and MMP-9 were normalized to that of GAPDH.

Statistical analysis. All statistical analyses were performed using SPSS version 11.0 software (SPSS, Inc., Chicago, IL, USA). Values are presented as the mean \pm standard deviation and were analyzed using two-tailed Student's t-test or one-way analysis of variance with Dennett's multiple comparison tests. $\mathrm{P}<0.05$ was considered to indicate a statistically significant difference between values.

\section{Results}

Effects of PTX and HM on the proliferation of SGC-7901 and MKN-45 cells. MTT assays were performed in order to analyze the metabolic activity of proliferating cells. The results demonstrated that PTX and HM inhibited the cell proliferation in a dose-dependent manner when administered individually (Fig. 2A and B). In addition, the inhibitory effects of combined treatment with PTX and HM on cell proliferation were significantly enhanced and produced marked inhibition at lower concentrations in SGC-7901 and MKN-45 cells $(\mathrm{P}<0.05$; Fig. 2C).

Effects of PTX and HM on the migration of SGC-7901 and MKN-45 cells. In order to evaluate the effects of PTX and HM on the invasion and metastasis of MKN-45 and SGC-7901 cells, Transwell ${ }^{\circledR}$ migration assays were performed. 
A
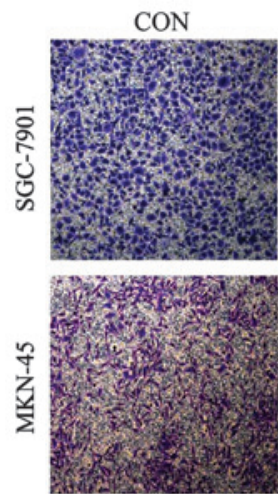

C
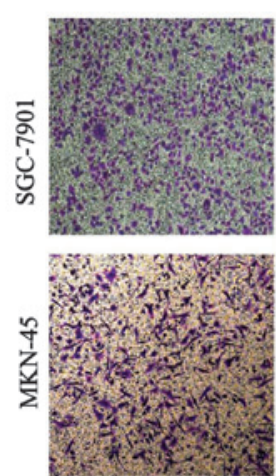

PTX
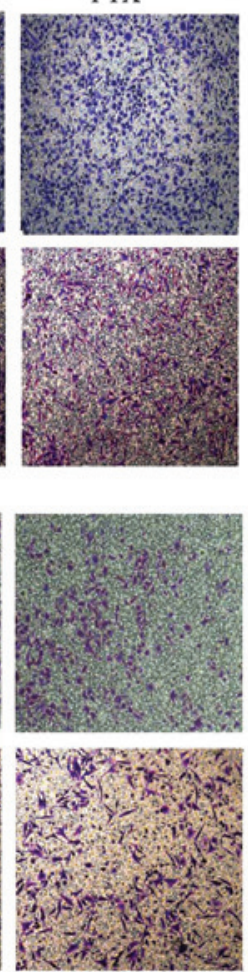

HM
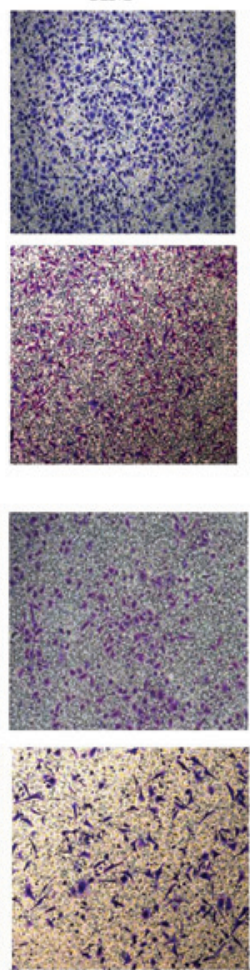

PTX+HM
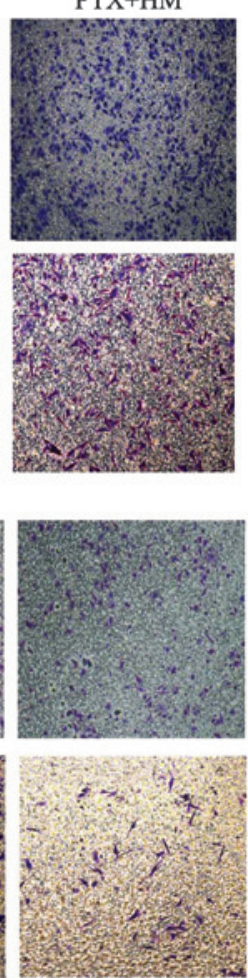

B

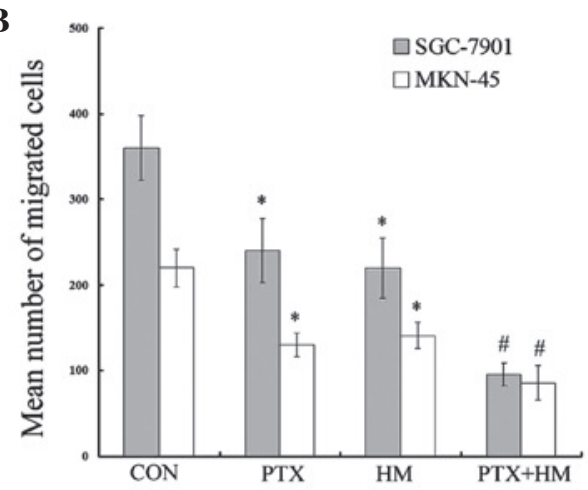

D

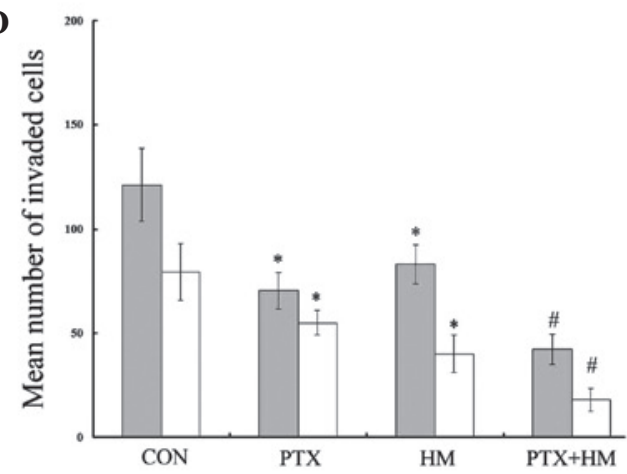

Figure 3. Effects of PTX and HM on the migration and invasion of SGC-7901 and MKN-45 gastric cancer cells. (A) Cell migration was observed using a Transwell ${ }^{\circledR}$ migration assay. (B) Quantification of the number of migrated cells. (C) Cell invasion was determined using a Transwell ${ }^{\circledR}$ invasion assay. (D) Quantification of the number of invaded cells. Values are presented as the mean \pm standard deviation. ${ }^{*} \mathrm{P}<0.05$, vs. control; and ${ }^{\#} \mathrm{P}<0.05$ vs. PTX or HM. PTX, paclitaxel; HM, harmine; CON, untreated control.

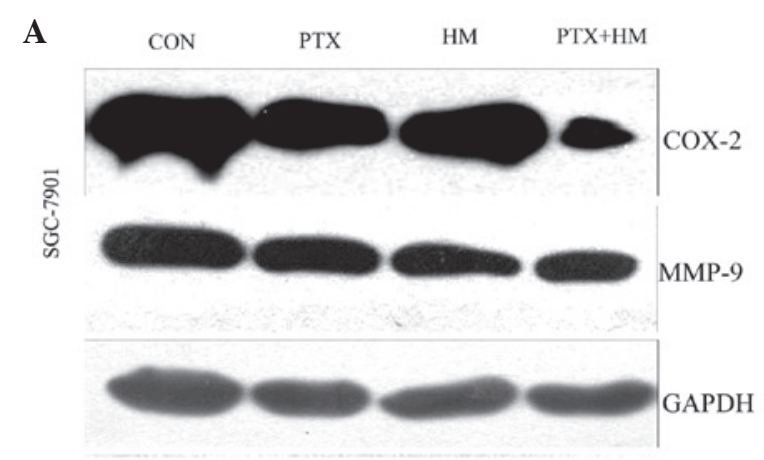

в

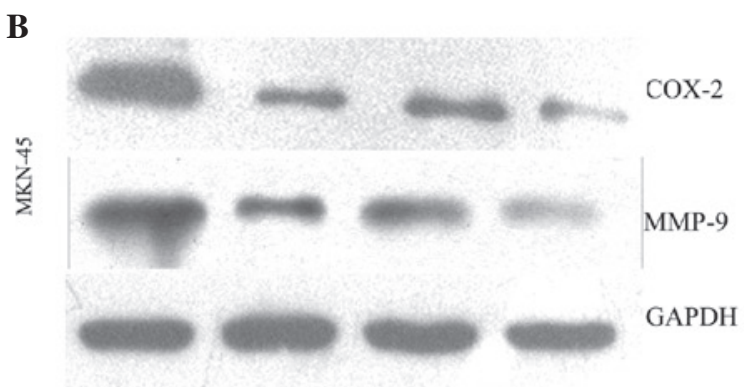

C

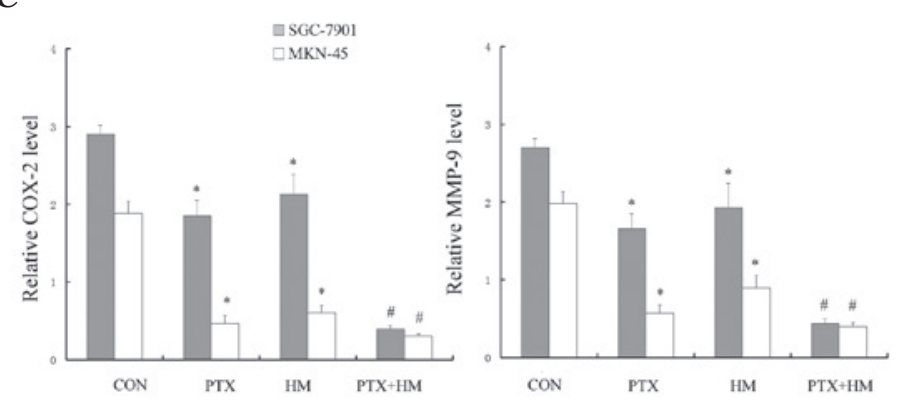

Figure 4. Effects of PTX and HM on COX-2 and MMP-9 protein expression in (A) SGC-7901 and (B) MKN-45 cells. GAPDH was used as an internal control. (C) Quantification of relative COX-2 and MMP-2 expression. Values are presented as the mean \pm standard deviation from three independent experiments. "P $<0.05$ vs. CON; and "P<0.05 vs PTX or HM. CON, untreated control; PTX, paclitaxel; HM, harmine; COX-2, cyclooxygenase-2; MMP-9, matrixmetalloproteinase-9.

As shown in Fig. 3A and B, the number of migrated cells in the individually-treated PTX and HM groups were significantly reduced compared with the control group $(\mathrm{P}<0.05)$.
In addition, the number of migrated cells in the combination group was further attenuated compared with the single drug groups $(\mathrm{P}<0.05)$. 
Effects of PTX and HM on the invasion of SGC-7901 and $M K N-45$ cells. The effects of PTX and HM on gastric cancer cell invasion were evaluated using Matrigel ${ }^{\circledR}$-coated Transwell $^{\circledR}$ invasion assays. The results demonstrated that, when treated individually, PTX and HM significantly inhibited the invasion ability of gastric cancer cells compared with the control group $(\mathrm{P}<0.05)$. In addition, the results clearly revealed that the combined treatment of PTX and HM resulted in a significant decrease in the number of invaded cells compared with the effects of either PTX or HM alone $(\mathrm{P}<0.05$; Fig. 3C and D).

Effects of PTX and HM on COX-2 and MMP-9 expression in SGC-7901 and MKN-45 cells. As determined using western blot analysis, the exposure of SGC-7901 and MKN-45 gastric cancer cells to PTX or HM, individually, markedly decreased the expression levels of COX-2 and MMP-9 (P<0.05; Fig. 4A and $\mathrm{B})$. In addition, the combined application of PTX and HM resulted in a further reduction in COX-2 and MMP-9 expression compared with the effects of either of drugs alone $(\mathrm{P}<0.05$; Fig. 4C).

\section{Discussion}

Gastric cancer, one of the most prevalent types of malignant tumors, is a major cause of cancer-associated mortality. Invasion and metastasis are important biological behaviors of malignant tumors which affect the prognosis and effective treatment of gastric cancer $(14,15)$. Invasion and metastasis are a complex and continuous multi-step process, for which degradation of the ECM is critical. It is therefore of great significance for reducing the metastasis of gastric cancer to take effective preventive measures against these processes. A previous study reported that the use of Traditional Chinese Medicine against invasion and metastasis in cancer is increasingly popular. Numerous studies have demonstrated that certain Traditional Chinese Medicines and their extracts may effectively inhibit tumor invasion and metastasis $(5,6)$.

Paclitaxel has been reported to be an important drug for treating gastric cancer, as it was shown to effectively prolong the survival time of gastric cancer patients and improve their quality of life (16). However, a number of clinical and experimental studies in recent years have discovered that several types of malignant tumors including breast cancer, lung cancer, ovarian cancer and gastric cancer exhibited primary or secondary drug resistance to paclitaxel (17). Therefore, it is important to explore a novel methods of enhancing the anticancer effect of PTX and to elucidate novel therapies that may reverse the resistance to PTX in cancer patients. Harmine (HM), a tricyclic compound belonging to the $\beta$-carboline alkaloids, has been demonstrated to inhibit migration and invasion in gastric cancer in vitro (6). However, the synergistic antitumor effect of a combined PTX and HM treatment on migration and invasion in human gastric cancer cells remained to be elucidated.

COX-2 is a molecular target for cancer prevention and treatment that has been extensively studied over the past decade (10). COX-2 overexpression was reported to be involved in the genesis and development of gastric cancer and was suggested to be closely associated with the invasiveness and metastasis of gastric cancer (6). It has been well-established that prostaglandins are synthesized from arachidonate under the catalytic effects of COX-2 and these prostaglandins may enhance the activity of several MMPs, strengthen CD44 expression and reduce the expression of epithelial cadherin, resulting in the reinforced invasiveness of tumors (18-20). It was previously demonstrated that HM significantly inhibited COX-2 expression in BGC-823 and SGC-7901 cells (6). The western blot analysis results of the current study revealed that the combined application of PTX and HM resulted in a marked decrease in the expression of COX-2 compared with the effects of either drug alone.

Tumor invasion and metastasis are known to be the major causes of morbidity and mortality in gastric cancer patients. Tumor cell-induced ECM and basement membrane degradation is a critical step in the processes of tumor invasion and metastasis (12). MMP-9, an important isoform in the MMP family, is considered to be closely correlated with tumor invasion and metastasis, which may be due to the degradation of type IV collagen (11). Numerous in vivo and in vitro data have demonstrated that inducing MMP-9 expression may be one of the mechanisms by which COX-2 promotes the development and metastasis of gastric cancer $(6,7)$. The present study has demonstrated that PTX combined with HM resulted in a marked decrease in COX-2 and MMP-9 expression compared with the effects of either of drugs alone in SGC-7901 and $\mathrm{MKN}-45$ cells. Furthermore, in vitro migration and invasion assays have confirmed that PTX combined with HM exerted an enhanced inhibitory effect on the migration and invasion of gastric cancer cells compared with that of individual treatments.

In conclusion, the present study demonstrated that PTX combined with HM inhibited the migration and invasion of human gastric cancer cells, the mechanism of which may proceed via the downregulation of COX-2 and MMP-9. It has been previously reported that overexpression of COX-2 was involved in apoptosis resistance, angiogenesis, decreased host immunity as well as enhanced invasion and metastasis. Further studies are required to elucidate whether the synergistic effect of PTX and HM also exerts in the gastric cancer in vivo.

\section{References}

1. Smith MG, Hold GL, Tahara E and El-Omar EM: Cellular and molecular aspects of gastric cancer. World J Gastroenterol 12: 2979-2990, 2006.

2. Lee JH, Kim KM, Cheong JH and Noh SH: Current management and future strategies of gastric cancer. Yonsei Med J 53: 248-257, 2012.

3. Sakamoto J, Matsui T and Kodera Y: Paclitaxel chemotherapy for the treatment of gastric cancer. Gastric Cancer 12: 69-78, 2009.

4. Cao MR, Li Q, Liu ZL, Liu HH, Wang W, Liao XL, Pan YL and Jiang JW: Harmine induces apoptosis in HepG2 cells via mitochondrial signaling pathway. Hepatobiliary Pancreat Dis Int 10: 599-604, 2011

5. Liao X, Che X, Zhao W, Zhang D, Bi T and Wang G: The $\beta$-adrenoceptor antagonist, propranolol, induces human gastric cancer cell apoptosis and cell cycle arrest via inhibiting nuclear factor $\kappa \mathrm{B}$ signaling. Oncol Rep 24: 1669-1676, 2010.

6. Zhang H, Sun K, Ding J, Xu H, Zhu L, Zhang K, Li X and Sun W: Harmine induces apoptosis and inhibits tumor cell proliferation, migration and invasion through down-regulation of cyclooxygenase-2 expression in gastric cancer. Phytomedicine 21: 348-355, 2014. 
7. Sun WH, Sun YL, Fang RN, Shao Y, Xu HC, Xue QP, Ding GX and Cheng YL: Expression of cyclooxygenase-2 and matrix metalloproteinase-9 in gastric carcinoma and its correlation with angiogenesis. Jpn J Clin Oncol 35: 707-713, 2005.

8. Huang F, Lin C, Shi YH and Kuerban G: MicroRNA-101 inhibits cell proliferation, invasion, and promotes apoptosis by regulating cyclooxygenase-2 in Hela cervical carcinoma cells. Asian Pac J Cancer Prev 14: 5915-5920, 2013.

9. Chan MW, Wong CY, Cheng AS, Chan VY, Chan KK, To KF, Chan FK, Sung JJ and Leung WK: Targeted inhibition of COX-2 expression by RNA interference suppresses tumor growth and potentiates chemosensitivity to cisplatin in human gastric cancer cells. Oncol Rep 18: 1557-1562, 2007.

10. Sun WH, Zhu F, Chen GS, Su H, Luo C, Zhao QS, Zhang Y, Shao Y, Sun J, Zhou SM, et al: Blockade of cholecystokinin-2 receptor and cyclooxygenase-2 synergistically induces cell apoptosis, and inhibits the proliferation of human gastric cancer cells in vitro. Cancer Lett 263: 302-311, 2008.

11. Ram M, Sherer Y and Shoenfeld Y: Matrix metalloproteinase-9 and autoimmune diseases. J Clin Immunol 26: 299-307, 2006.

12. Velinov N, Poptodorov G, Gabrovski N and Gabrovski S: The role of matrixmetalloproteinases in the tumor growth and metastasis. Khirurgiia (Sofiia) 1: 44-49, 2010 (In Bulgarian).

13. He XP, Shao Y, Li XL, Xu W, Chen GS, Sun HH, Xu HC, Xu X, Tang D, Zheng XF, et al: Downregulation of miR-101 in gastric cancer correlates with cyclooxygenase- 2 overexpression and tumor growth. FEBS J 279: 4201-4212, 2012.

14. Liu W, Yang Q, Liu B and Zhu Z: Serum proteomics for gastric cancer. Clin Chim Acta 431: 179-184, 2014.
15. Neugut AI, Hayek M and Howe G: Epidemiology of gastric cancer. Semin Oncol 23: 281-291, 1996.

16. Tuan TF, Tsai ML, Yeh KC, Huang HC, Chung CT, Huang CL, Han $\mathrm{CH}$, Chen $\mathrm{CP}$, Wang $\mathrm{MH}$, Shen $\mathrm{CC}$, et al: Intravenous paclitaxel against metastasis of human gastric tumors of diffuse type. Cancer Chemother Pharmacol 66: 773-783, 2010.

17. Papadaki C, Mavroudis D, Trypaki M, Koutsopoulos A, Stathopoulos E, Hatzidaki D, Tsakalaki E, Georgoulias V and Souglakos J: Tumoral expression of TXR1 and TSP1 predicts overall survival of patients with lung adenocarcinoma treated with first-line docetaxel-gemcitabine regimen. Clin Cancer Res 15: 3827-3833, 2009.

18. Williams CS, Smalley W and DuBois RN: Aspirin use and potential mechanisms for colorectal cancer prevention. J Clin Invest 100: 1325-1329, 1997.

19. O'Mahony CA, Beauchamp RD, Albo D, Tsujii M, Sheng HM, Shao J, Dubois RN and Berger DH: Cyclooxygenase-2 alters transforming growth factor-beta 1 response during intestinal tumorigenesis. Surgery 126: 364-370, 1999.

20. Liu XH, Kirschenbaum A, Yao S, Stearns ME, Holland JF Claffey $\mathrm{K}$ and Levine AC: Upregulation of vascular endothelial growth factor by cobalt chloride-simulated hypoxia is mediated by persistent induction of cyclooxygenase-2 in a metastatic human prostate cancer cell line. Clin Exp Metastasis 17: 687-694, 1999. 